\title{
Cellular senescence in the aging and diseased kidney
}

\author{
F. A. Valentijn ${ }^{1}$ L. L. Falke ${ }^{1,2} \cdot$ T. Q. Nguyen ${ }^{1} \cdot$ Roel Goldschmeding $^{1}$ (D)
}

Received: 2 November 2017 / Accepted: 3 November 2017 /Published online: 19 December 2017

(C) The Author(s) 2017. This article is an open access publication

\begin{abstract}
The program of cellular senescence is involved in both the G1 and G2 phase of the cell cycle, limiting G1/S and $\mathrm{G} 2 / \mathrm{M}$ progression respectively, and resulting in prolonged cell cycle arrest. Cellular senescence is involved in normal wound healing. However, multiple organs display increased senescent cell numbers both during natural aging and after injury, suggesting that senescent cells can have beneficial as well as detrimental effects in organismal aging and disease. Also in the kidney, senescent cells accumulate in various compartments with advancing age and renal disease. In experimental studies, forced apoptosis induction through the clearance of senescent cells leads to better preservation of kidney function during aging. Recent groundbreaking studies demonstrate that senescent cell depletion through INK-ATTAC transgene-mediated or cell-penetrating FOXO4-DRI peptide induced forced apoptosis, reduced age-associated damage and dysfunction in multiple organs, in particular the kidney, and increased performance and lifespan. Senescence is also involved in oncology and therapeutic depletion of senescent cells by senolytic drugs has been studied in experimental and human cancers. Although studies with senolytic drugs in models of kidney injury are lacking, their dose limiting side effects on other organs suggest that targeted delivery might be needed for successful application of senolytic drugs for treatment of kidney disease. In this review, we discuss (i) current understanding of the mechanisms and associated pathways of
\end{abstract}

Roel Goldschmeding

R.Goldschmeding@umcutrecht.nl

1 Department of Pathology, University Medical Center Utrecht, H04.312, Heidelberglaan 110, 3584, CX Utrecht, The Netherlands

2 Department of Internal Medicine, Diakonessenhuis, Utrecht, The Netherlands senescence, (ii) evidence of senescence occurrence and causality with organ injury, and (iii) therapeutic strategies for senescence depletion (senotherapy) including targeting, all in the context of renal aging and disease.

Keywords Apoptotic balance - DNA damage response . Cellular senescence $\cdot$ Renal aging $\cdot$ Renal disease . Senotherapy

\section{Renal aging and disease}

The pathophysiological substrate of chronic kidney disease (CKD) is kidney injury leading to fibrosis and reduced kidney function reflected in a lower glomerular filtration rate (GFR). This might be due to the normal wear and tear associated with aging, and/or to renal disease. In the developed world, life expectancy has increased substantially and this is accompanied by a growing portion of the population, particularly elderly, diagnosed with CKD (Coresh et al. 2007). In 2016, the global prevalence of CKD was estimated to be as much as $13.4 \%$, forming a global health burden with a high economic cost to health systems worldwide (Hill et al. 2016). CKD patients are highly susceptible to additional injury, subsequent development of end stage renal disease (ESRD) and ultimately death, all of which are thought to be caused by lack of adequate repair. The mechanisms leading to fibrosis in both renal aging and renal damage are complex and involve multiple pathological phenomena and signaling pathways, such as pro-inflammatory/fibrotic signaling, loss of renoprotective factors (e.g. Klotho and bone morphogenetic proteins), vascular rarefaction and oxidative stress (O'Sullivan et al. 2017). A relatively new theory suggests involvement of cellular senescence as a central process in both early and late phases of renal aging and injury, connecting existing mechanisms of fibrosis. 


\section{Cellular senescence and associated pathways}

Cellular senescence traditionally refers to a permanent cell cycle arrest (CCA) that can be initiated by various cellular stresses despite the presence of growth-inducing stimuli. This is opposed to quiescence, which is a temporary state of CCA due to a lack of growth stimulation (Blagosklonny 2011). Senescence has typically been linked to the G1-phase of the cell-cycle, but it does occur also in G2 (see below) (Stein and Dulić 1995; Smith and Pereira-Smith 1996). Major triggers of senescence include repeated cell division and telomere shortening (also referred to as replicative senescence), and factors such as oxidative stress or genotoxic injury (stress-induced premature senescence) (Fig. 1) (Campisi 1997; Toussaint et al. 2000). Additionally, a number of cytokines/growth factors have been implicated to induce senescense, including transforming growth factor- $\beta$ (TGF- $\beta$ ) and the matricellular protein CCN1 (Datto et al. 1995; Jun and Lau 2010; Kim et al. 2013). Mechanistically, senescent cells can act cell-autonomously by induction of CCA and non-cellautonomously by influencing neighboring cells through proteins that are part of the senescence-associated secretory phenotype (SASP) (Xue et al. 2007).

\section{Senescence-associated secretory phenotype}

Senescent cells have a distinct secretome termed the senescence-associated secretory phenotype (SASP)(Krtolica et al. 2001; Coppé et al. 2008). Via this SASP, senescent cells affect neighboring cells by producing pro-fibrotic and proinflammatory factors, including interleukin 6 , plasminogen activator inhibitor-1 (PAI-1), TGF- $\beta$ and connective tissue growth factor (CCN2/CTGF), several of which are considered markers of senescence (Table 1)(Matjusaitis et al. 2016a). Normally, this immunogenic phenotype is part of a cancer defense mechanism that enables senescent cells to be eliminated (senescent-cell clearance) by the immune system through a process known as immune surveillance (Kang et al. 2011). However, an impaired immune system due to aging, disease or immunosuppressive therapy may cause senescent cells to evade elimination and maintain their metabolic activity. Although the exact composition of the SASP secrotome is unknown, it is considered to be a driving force behind senescence-induced fibrosis of the kidney (Sturmlechner et al. 2017).

Senescent cells express a broad spectrum of features, rendering a distinct morphology in vivo (reviewed by ref. (Sharpless and Sherr 2015)). Typical phenotypic traits are permanent CCA, persistent DDR, SASP, epigenetic changes like senescence-associated heterochromatic foci (SAHFs), altered metabolism including increased lysosomal and proteasomal activity, and telomere shortening and dysfunction (Sharpless and Sherr 2015; Matjusaitis et al. 2016b). The most commonly used biomarkers of senescence are senescence-associated $\beta$-galactosidase (SA- $\beta$-Gal) and p16. (,,(Dimri et al. 1995; Krishnamurthy et al. 2004; Burd et al. 2013)). Despite the availability of several markers and detection techniques (e.g. immunohistochemistry), accurate detection of senescent cells is complicated by (i) heterogeneity of senescent cells, (ii) organismal and possibly even individual variation of senescent markers and (iii) low sensitivity and specificity of senescent markers. (Gil and Peters 2006; Aan et al. 2013). Therefore, it is important to use combinations of different markers to reliably identify senescent cells.

\section{Prolonged cell-cycle arrest}

Prolonged CCA is a key feature of senescence and is mediated via induction of the DDR. Following DNA damage, the DDR arrests cell cycle progression at specific checkpoints, particularly the G1/S checkpoint, thereby allowing time for DNA repair to prevent that errors are replicated or passed on to daughter cells in mitosis (Jackson and Bartek 2009). Cells with repairable DNA lesions go into transient CCA (quiescence), eventually re-entering the cell cycle in case of adequate DNA damage response by the DDR machinery. In contrast, severe or irreparable DNA lesions trigger prolonged DDR signaling, resulting in apoptosis or permanent growth arrest (senescence) (Campisi and d'Adda di Fagagna 2007).

Senescence is classically linked to the G1-phase of the cellcycle (Stein and Dulić 1995; Smith and Pereira-Smith 1996). (,) However, accumulating evidence indicates that senescence also occurs in the G2 phase, generally referred to as G2-arrest. (reviewed in ref. (Gire and Dulic 2015). It is widely accepted that senescence associated prolonged G1- and G2-arrest occurs via late anti-proliferative DDR signaling in response to persistent DNA damage (Malaquin et al. 2015). Cell cycle progression requires activation of cyclin dependent kinases (CDKs). DDR induced prolonged CCA in senescence is characterized by accumulation of cyclin dependent kinase inhibitors (CKIs) like tumor protein p53 (TP53 or p53), p21 ${ }^{\mathrm{CIP} 1}$ (p21) and $\mathrm{p} 16^{\mathrm{INK} 4 \mathrm{a}}(\mathrm{p} 16)$ (el-Deiry et al. 1993; Harper et al. 1993). These CKIs inactivate CDKs and block CDK-mediated phosphorylation of the retinoblastoma tumor suppressor $(\mathrm{Rb})$. This causes $\mathrm{Rb}$ to remain attached to and thereby inhibit the transcriptionally active E2F protein complex, thus preventing G1/S transition and DNA replication, or G2/M progression and mitosis, ultimately limiting cellular proliferation (Zhang et al. 1993; Serrano et al. 1993; Jullien et al. 2013) (Fig. 2).

Several relevant differences between G1- and G2-arrest are postulated. Firstly, replicative senescence applies mainly to G2 arrest as telomere attrition preferentially triggers DDR at the G2/M checkpoint (d'Adda di Fagagna 2008; Jullien et al. 2013; Mao et al. 2014). Secondly, p53 mediates senescence 
Fig. 1 The cell cycle, relevant cell cycle arrest points, and their inducers and associated markers

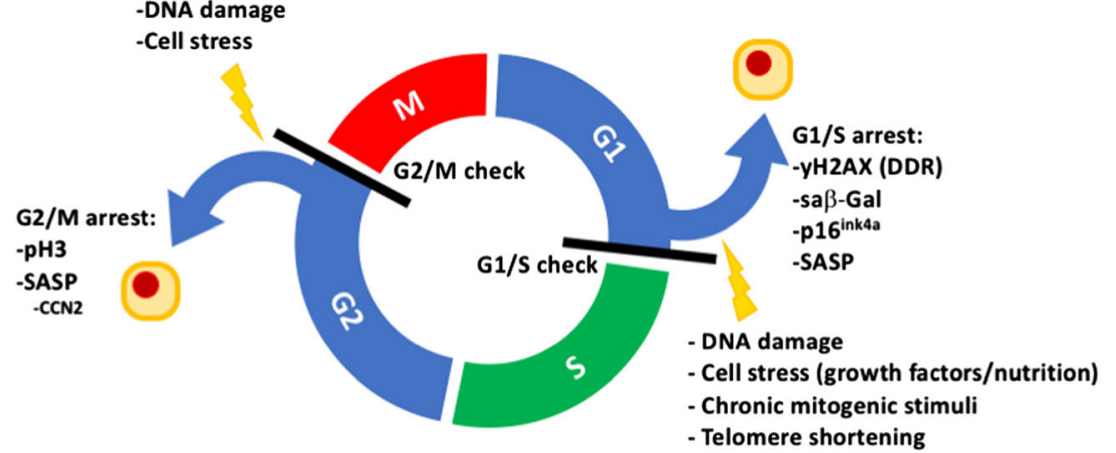

independent of p21 in the G2 phase (Johmura et al. 2014). Thirdly, the G2/M checkpoint is not as efficient in inducing CCA as the G1-S checkpoint, which relies on strong p21 induction (Löbrich and Jeggo 2007; Cesare et al. 2013). Prolonged (i.e. senescent) G2-arrested cells express enhanced levels of profibrotic growth factors like TGF- $\beta 1$ and CCN2 (Yang et al. 2010). Hence, the term "maladaptive regeneration/repair" has been postulated (Bonventre 2014a). Yet, to our knowledge the only specific marker for G2-arrest to date is histone $\mathrm{H} 3$ phosphorylation at Ser10 (p-H3), as cells in G2 phase show a distinct phosphorylation and IHC staining pattern of $\mathrm{p}-\mathrm{H} 3$. Other markers to make a clear distinction between G1and G2-arrested cells are lacking, and also the possible variability of the exact composition of the SASP, is still poorly defined, thus it seems appropriate to refer to cellular senescence-like features, rather than suggesting that these identify a homogeneous phenotype (Crosio et al. 2002; Yang et al. 2010).

\section{The apoptotic balance}

The $\mathrm{p} 53$ protein plays an important role in controlling cell fate by mediating temporary CCA, senescence, or apoptosis in case of irreversible DNA damage. The absolute levels of p53 expression seem to be decisive in determining cell fate (Khoo et al. 2014). High levels of p53 lead to apoptosis and lower levels result in temporary CCA (Chen et al. 1996; Kracikova et al. 2013). However, the effect of p53 on senescence remains unclear. Thus far, low levels of p53 have only been described to induce temporary CCA. In case of irreversible DNA damage, p53 plays a prominent role in DDRmediated apoptosis via induction and inhibition of proapoptotic and anti-apoptotic proteins, respectively (reviewed by ref. (Khoo et al. 2014)). Pro-apoptotic proteins like phorbol-12-myristate-13-acetate-induced protein 1 (PMAIP1; also known as NOXA) and p53-upregulated modulator of apoptosis (PUMA) bind and inhibit multiple mitochondrial anti-apoptotic BCL family members (Chen et al. 2005). Pro-apoptotic proteins that are directly upregulated by $\mathrm{p} 53$ also include BAX and p53-inducible protein 3 (PIG3) (Samuels-Lev et al. 2001).

The exact mechanisms of p53 and its impact on the pro/ anti-apoptotic balance in senescence remain unclear. Strikingly, senescent IMR90 cells show upregulation of proapoptotic PUMA and BIM and reduced anti-apoptotic BCL-2, but this does not induce these cells to actually undergo

Table 1 Features of senescent cells

\begin{tabular}{lll}
\hline Feature & Senescence marker & Method of detection \\
\hline $\begin{array}{c}\text { Senescence-associated } \\
\text { secretory phenotype }\end{array}$ & $\begin{array}{l}\text { Cytokines (IL-6, IL-8, GRO } \alpha \text {, GRO } \beta \text {, IL- } \alpha \text {, PAI-1, CCL2/MCP-1) } \\
\text { Growth factors (GM-CSF, G-CSF, HGF/SF, IGF, TGF- } \beta, \text { CCN2/CTGF) }\end{array}$ & ELISA, FACS \\
& $\begin{array}{l}\text { Proteases (MMP-1, -2, and -3) } \\
\text { Non-soluble extracellular matrix proteins } \\
\text { (collagens, fibronectin, laminin) }\end{array}$ & \\
& DNA damage markers $(\gamma \mathrm{H}$ AX, ATM, ATR, TP53, Rad17, MDC1, TIF) & IHC \\
DNA-associated & DNA synthesis (Ki67, EdU, BrdU) & Ki67 IHC; EdU or BrdU incorporation \\
& Telomere length/dysfunction & qPCR, FISH \\
& Epigenitic changes (senescence-associated heterochomatin foci) & CiA, DAPI staining, IHC \\
DNA-damage response & Proteasome activity & Fluorogenic peptide substrate assay \\
& Lysosomal activity ( $\beta$-galactosidase, $\alpha$-Fucosidase) & IHC, qPCR, EM, WB \\
& ROS & DCFDH-DA fluorometry, chemiluminescent \\
& & oxygen detection reagents, FACS \\
Cell cycle arrest & Cyclin-dependent kinase inhibitors & IHC, qPCR \\
& (p21CIP1, p16INKa, p19ARF, p14ARF, p27KIP1, p15Ink4b) & \\
\hline
\end{tabular}

Abbreviations: $\mathrm{IHC}=$ immunohistochemistry; $\mathrm{qPCR}=$ quantitative $\mathrm{PCR} ; \mathrm{EM}=$ electron microscopy; WB = Western blot 
$\mathrm{G} 1 / \mathrm{S}$ cell cycle arrest

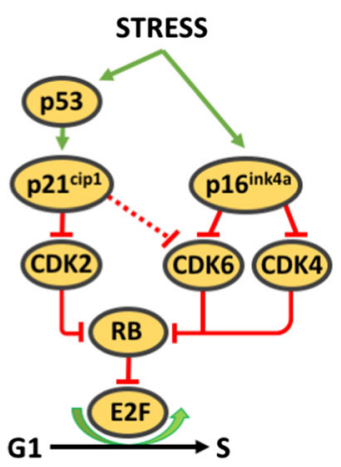

G2/M cell cycle arrest

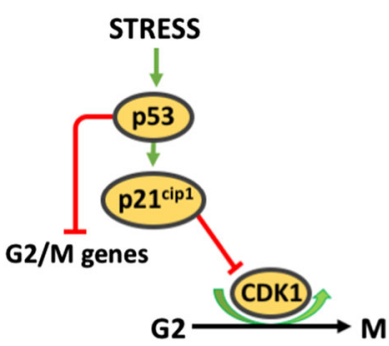

Fig. 2 Cell cycle arrest signaling. Left panel: Major signaling pathway associated with G1S arrest. Right panel: Major signaling pathway associated with G2 M arrest

apoptosis (Baar et al. 2017). This evasion of apoptosis could be explained by secondary factors that influence the function of p53, thereby favoring senescence over apoptosis. Such factors include the Forkhead box protein $\mathrm{O} 4$ (FOXO4) that binds and retains p53 to persistent nuclear foci containing DDR proteins termed 'DNA segments with chromatin alterations reinforcing senescence' (DNA-SCARS) that associate with PML (promyelocytic leukemia protein) nuclear bodies (Rodier et al. 2011; Baar et al. 2017). The association between DNA-SCARS en PML nuclear bodies, where many repair and chromatin-modifying proteins localize, promotes senescence-associated gene expression (Rodier et al. 2011). An anti-apoptotic role has also been assigned to CCN2 in various organs and tissues, including mesangial cells of human kidneys (Wahab et al. 2007).

\section{Evidence for senescence in the kidney from observational studies}

It is a well-established fact that senescent cell numbers are increased during physiological renal aging as well as in response to renal injury. Tables 2 and 3 lists available reports to date, regarding quantification of senescent cell numbers in the human kidney during renal physiological aging and disease, and their relation with glomerulosclerosis and/or interstitial injury. To what extent senescence might be an epiphenomenon, or causally linked to clinically relevant parameters such as renal interstitial and/or glomerular disease and renal functionality, remains controversial and is further discussed below.

\section{Senescence in renal aging}

To date no published data are available that specifically address G2 arrest in aging kidneys. However, varying combinations of senescence markers, such as p16 and SA- $\beta-$ Gal, have consistently been found to be increased in aged kidneys (Table 2). Thus, increased numbers of senescent cells were found in association with glomerulosclerosis and tubulointerstitial changes (Ding et al. 2001; Chkhotua et al. 2003; Melk et al. 2003; Melk et al. 2004). Additionally, in a murine model of allograft nephropathy, old donor kidneys displayed increased p16 levels, a reduced proliferation of tubular epithelial cells after transplantation, and increased susceptibility to transplantation related stress compared to kidneys from young donors (Melk et al. 2009). Also, old mice display a relatively higher increase of SA- $\beta$-Gal, p 53 and p 21 ,

Table 2 Observations regarding quantification of senescent cell numbers in renal aging

\begin{tabular}{|c|c|c|c|c|}
\hline Study & $\begin{array}{l}\text { Species } \\
\text { (comparison or range in age) }\end{array}$ & Senescence marker & Sublocalization & Association with aging \\
\hline \multicolumn{5}{|l|}{ Aging } \\
\hline (Krishnamurthy et al. 2004) & Mouse and rat (3 vs 28 months) & SA- $\beta-G a l, p 16$, p19 & Cortical tubules & Nephritis \\
\hline (Chkhotua et al. 2003) & Human (21-80 years) & $\mathrm{p} 16, \mathrm{p} 27$ & Cortical tubules and Interstitium & Nephron atrophy \\
\hline (Melk et al. 2004) & Human ( 8 weeks-88 years) & $\mathrm{p} 16, \mathrm{p} 53$, TGF $\beta 1, \mathrm{p} 14$ & Glomeruli, tubules, arteries & $\begin{array}{l}\text { Glomerulosclerosis, } \\
\text { interstitial fibrosis } \\
\text { and tubular atrophy }\end{array}$ \\
\hline (Ding et al. 2001) & Rat (3 vs12 vs 24 months) & SA- $\beta$-gal, TGF- $\beta 1$, p 21 & Tubulointerstitium & $\begin{array}{l}\text { Interstitial fibrosis and } \\
\text { tubular atrophy }\end{array}$ \\
\hline (Melk et al. 2003) & Rat (9-24 months) & p16, SA- $\beta$-gal & Glomeruli, tubulointerstitium & Interstitial fibrosis \\
\hline (Sis et al. 2007) & Human (mean age 36.4 years) & p16 & $\begin{array}{l}\text { Glomeruli, tubulointerstitium, } \\
\text { arteries }\end{array}$ & None \\
\hline \multicolumn{5}{|c|}{ Aging in (a model of) renal transplantation } \\
\hline (Melk et al. 2009) & Mouse ( 3 vs 18 months) & p16, Ki-67 & Glomeruli, tubulointerstitium & $\begin{array}{c}\text { Tubular atrophy, reduced } \\
\text { tubular proliferation }\end{array}$ \\
\hline (Clements et al. 2013) & Mouse $8-10$ vs $46-49$ weeks) & SA- $\beta-G a l, p 53$, p 21 & Tubules & $\begin{array}{l}\text { Mortality and kidney } \\
\text { function, interstitial } \\
\text { fibrosis, inflammation }\end{array}$ \\
\hline (Chkhotua et al. 2003) & Human (19-60 years) & $\mathrm{p} 16, \mathrm{p} 27$ & Glomeruli, tubulointerstitium & None \\
\hline
\end{tabular}




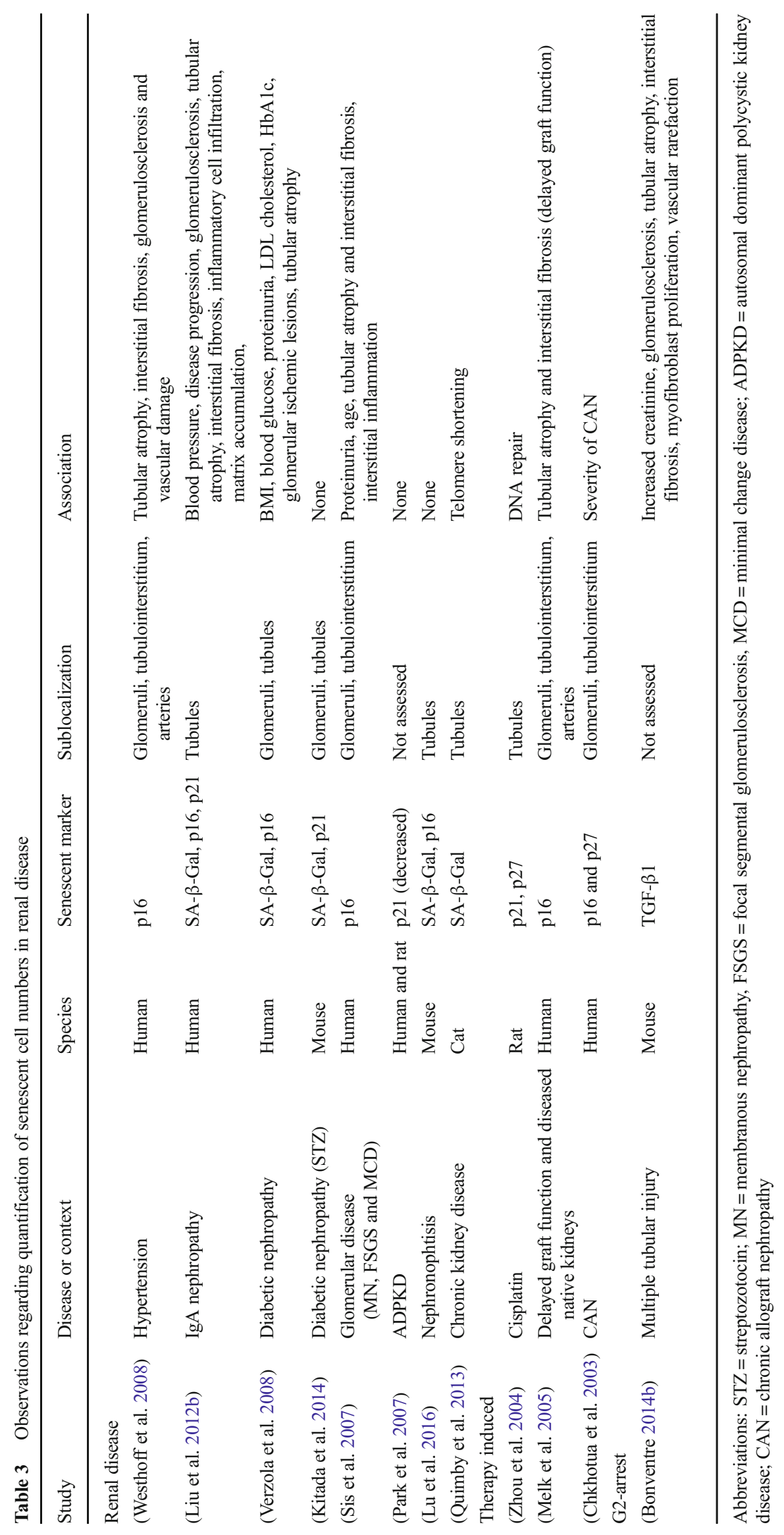


compared to young mice upon IRI (Clements et al. 2013). () Together, these observations suggest an age-dependent increase in the susceptibility of the kidney to induction of senescence and concomitantly reduced regenerative capacity.

\section{Senescence in renal disease}

In response to injury, renal senescent cell numbers, indicated by varying combinations of markers mainly consisting of SA- $\beta-G a l, p 16$ and $p 21$ expression, are increased in various experimental animal models and human renal diseases (Table 3). For example, an increase of senescence markers was observed upon renal injury in rodent models including DOCA-salt-induced hypertension, streptozotocin (STZ)-induced diabetic nephropathy (DN), and cisplatin-induced nephrotoxicity (Zhou et al. 2004; Westhoff et al. 2008; Kitada et al. 2014). Increased expression of senescence markers has also been found in diseased human and mouse kidneys in hypertension, DN, CKD, delayed graft function (DGF) after kidney transplantation, and in various glomerular diseases, including membranous nephropathy, minimal change disease, IgA nephropathy (IgAN) and focal segmental glomerulosclerosis (FSGS)) (Melk et al. 2005; Sis et al. 2007; Westhoff et al. 2008; Verzola et al. 2008; Liu et al. 2012a; Quimby et al. 2013). Importantly, in hypertension, DN, MG, IgAN, FSGS and also in DGF after renal transplantation, senescent cell accumulation correlated with renal histopathological changes (glomerulosclerosis, tubular atrophy, and interstitial fibrosis), with renal function, and/or with proteinuria, while in IgAN, tubular expression of p16, p21 and SA-betagal also correlated with blood pressure(Liu et al. 2012b). In $\mathrm{DN}$, tubular SA- $\beta$-Gal expression correlates with body mass index (BMI) and blood glucose, and tubular p16 is associated with BMI, LDL cholesterol and HbA1c (Verzola et al. 2008). Furthermore, the increment of renal senescent cells was associated with disease progression in IgAN (Liu et al. 2012b).

In line with these observations, therapeutic intervention in rodents reduced the accumulation of senescent cells induced by DOCA-salt, STZ and cisplatin respectively (Zhou et al. 2004; Westhoff et al. 2008; Kitada et al. 2014). Remarkably, only one study failed to show a relation between senescent cell accumulation and disease progression, where in kidney biopsies from diabetic patients with proteinuria, both p16 and SA- $\beta$-Gal were strongly upregulated in an early phase, but did not further increase during disease progression (Verzola et al. 2008).

Taken together, these data indicate that cellular senescence is associated with detrimental effects contributing to histopathological and functional deterioration and that it can be caused by various distinct disease-associated triggers. Moreover, it appears that in various diseases of the kidney senescence might be prevented or overcome by the application of appropriate therapeutic strategies. Thus, disease- and therapy-induced damage might induce renal senescence and contribute to histopathological and functional changes in the kidney and even play a deleterious role in disease progression. These detrimental effects of senescence could be explained by (i) reduced organ function via SASP effects, (ii) persistence of functionally incompetent cells, and (iii) impairment of the proliferation required to replace damaged cells.

\section{Type and localization of renal senescent cells}

In the aging or injured kidney, senescent cells have been found in both the medulla and cortex, and include tubular, glomerular, interstitial and vascular cells. Senescent cells are predominantly found in the cortex and represent mainly proximal tubular cells (PTC). This holds true especially G2-arrested senescent cells (Yang et al. 2010; Bonventre 2014a). Markers of senescence are also found in glomeruli of diseased kidneys, including DN, membranous nephropathy, FSGS, minimal change disease and glomerulonephritis (Melk et al. 2005; Sis et al. 2007; Verzola et al. 2008). The affected cell types in these conditions are podocytes, mesangial and/or endothelial cells, and parietal epithelia cells. Interstitial and vascular cells are among the cell types undergoing senescence in hypertension and glomerular disease (Sis et al. 2007; Westhoff et al. 2008). Thus, the type and localization of senescent cells seems to be dependent on the specific stressors involved and on the exact location of injury. In the context of aging, senescence might be induced mainly in tubular cells due to increased oxidative and cellular stress (Melk et al. 2004). Although tubular epithelium also seems to account for the majority of senescent cells in renal disease, other cell types may be affected as well, corresponding with the location of injury. For instance, kidneys with glomerular disease typically display increased expression of p16 in glomerular cell nuclei (Sis et al. 2007).

\section{Eliminating senescent cells in renal injury}

Possible benefits of intervention in the process of senescence have been explored through transgenic depletion and pharmaceutical inhibition or elimination of senescent cells (i.e. senotherapy). Table 4 summarizes the data published to date regarding the depletion or inhibition of formation of senescent kidney cells in experimental kidney injury. Many mouse studies have shown already that depletion/inhibition of senescent cells via genetic modification or pharmaceutical inhibition reduces renal injury, while senotherapeutics have been studied less extensively in the kidney and are discussed in the next section. In the context of aging, senescent cell depletion through the INK-ATTAC transgene that removes p16(Ink4a)-positive senescent cells upon drug treatment, 
Table 4 Outcome of intervention of senescence in renal aging and after kidney injury in mice

\begin{tabular}{|c|c|c|c|c|}
\hline Study & $\begin{array}{l}\text { Model of } \\
\text { kidney injury }\end{array}$ & $\begin{array}{l}\text { Method of } \\
\text { senescence } \\
\text { intervention }\end{array}$ & $\begin{array}{l}\text { Acute and long-term outcome } \\
\text { (days after kidney injury) }\end{array}$ & Effect of senescence \\
\hline (Baker et al. 2016) & $\begin{array}{l}\text { Natural aging } \\
\quad(1 \text {-year old })\end{array}$ & p16-KO & Attenuated glomerulosclerosis & Detrimental: contributing to renal aging \\
\hline (Wolstein et al. 2010) & UUO & p16-KO & Acute (10d): increased renal fibrosis & $\begin{array}{l}\text { Beneficial: part of anti-fibrotic } \\
\text { mechanism }\end{array}$ \\
\hline (Megyesi et al. 2001) & IRI & $\mathrm{p} 21-\mathrm{KO}$ & $\begin{array}{l}\text { Acute }(<7 \mathrm{~d}) \text { : impaired renal recovery, } \\
\text { higher renal damage, higher mortality }\end{array}$ & $\begin{array}{l}\text { Beneficial: responsible for recovery } \\
\text { after acute ischemic renal failure }\end{array}$ \\
\hline (Baisantry et al. 2016) & IRI & ATG5-KO & $\begin{array}{l}\text { Acute ( } 3 \mathrm{~d}) \text { : increased renal damage, } \\
\text { increased cell death } \\
\text { Long-term ( } 30 \mathrm{~d}) \text { : attenuated interstitial } \\
\text { fibrosis, better kidney function }\end{array}$ & $\begin{array}{l}\text { Beneficial: responsible for recovery } \\
\text { after acute ischemic renal failure } \\
\text { Detrimental: promoting renal fibrosis }\end{array}$ \\
\hline (Lee et al. 2012) & IRI & INK4a-KO & $\begin{array}{l}\text { Long term: improved kidney regeneration } \\
\text { (14d), decreased capillary } \\
\text { rarefaction }(1-28 \mathrm{~d})\end{array}$ & Detrimental: promoting renal fibrosis \\
\hline (Braun et al. 2012) & $\begin{array}{l}\text { Kidney } \\
\text { transplantation }\end{array}$ & p16-KO & $\begin{array}{l}\text { Long term (21d): reduced interstitial } \\
\text { fibrosis, reduced nephron atrophy }\end{array}$ & $\begin{array}{l}\text { Detrimental: contributing to adverse } \\
\text { long-term allograft outcomes }\end{array}$ \\
\hline (Hochegger et al. 2007) & IRI & $\begin{array}{l}\text { p53 inhibition via } \\
\text { pifithrin- } \alpha\end{array}$ & $\begin{array}{l}\text { Acute ( }<48 \mathrm{~h} \text { of reperfusion): reduced } \\
\text { serum creatinine, reduced tubular } \\
\text { necrosis score }\end{array}$ & $\begin{array}{l}\text { Detrimental: contributing to acute renal } \\
\text { failure after ischemia }\end{array}$ \\
\hline (Yang et al. 2010) & IRI, AAN, UUO & $\begin{array}{l}\text { p53 inhibition via } \\
\text { pifithrin- } \alpha\end{array}$ & Reduced fibrosis & Detrimental: promoting renal fibrosis \\
\hline
\end{tabular}

Abbreviations: $\mathrm{IRI}=$ ischemia reperfusion injury; $\mathrm{UUO}=$ unilateral ureteral obstruction; $\mathrm{AAN}=$ acute aristolochic acid toxic nephropathy; $\mathrm{KO}=$ genetic knock-out

leads to attenuated glomerulosclerosis and lower blood urea nitrogen levels later in life (Baker et al. 2016). In contrast, knockdown of p16 increased renal fibrosis following unilateral ureteral obstruction (UUO), indicating a beneficial effect of senescence on tissue remodeling upon acute kidney injury (Wolstein et al. 2010). Similarly, deletion of p21 and autophagy protein 5 (ATG5, which is critically involved in tubular epithelial senescence) aggravated ischemia-reperfusion injury (IRI), leading to increased renal damage and cell death, impaired renal recovery and higher mortality (Megyesi et al. 2001; Baisantry et al. 2016). On the other hand, inactivation of p16 or ATG5 resulted in reduction of interstitial fibrosis and nephron atrophy later after IRI, indicating a protective longterm effect of inhibition of senescence on the development of fibrosis (Lee et al. 2012; Braun et al. 2012; Baisantry et al. 2016). Furthermore, pharmaceutical p53 and JNK inhibition led to reduced numbers of G2-arrested cells together with less fibrosis in a model of severe bilateral IRI (Yang et al. 2010).

In summary, the fact that senescent-cell depletion induces a maladaptive, fibrotic repair response in UUO-related obstructive injury and in in the acute phase after IRI, while it leads to less apoptosis and enhanced regenerative proliferation in the chronic phase after IRI (O'Sullivan et al. 2017) points to a beneficial effect of cellular senescence in the early phase of acute kidney injury, where it might support regeneration while, in contrast, prolonged senescence during later stages appears to have detrimental effects in more chronic renal injury, a feature demonstrated in Fig. 3. Of note, similar paradoxical effects have been attributed to cellular senescence also in other conditions, including tumor biology and liver regeneration, where SASP can mediate paracrine effects of senescent cells, inducing either stemness or senescence in neighboring cells, depending on short or long duration, respectively (Ritschka et al. 2017). Obviously, this timedependent effect on outcome will be of key importance for translational opportunities. For example, in kidney transplantation, acute as well as chronic factors may drive accumulation of senescent cells. These include tacrolimus nephrotoxicity which, in rodents, involves the production of ROS and subsequent DDR, and possibly also reduction of physiological clearance of senescent cells as a result of immunosuppressive therapies (Khanna and Pieper 2007).

The interpretation and applicability of experimental studies with reference to human kidney aging and disease is complex. Renal disease models are mostly performed in young rodents and of relatively short duration. They thereby reflect acute, rather than chronic kidney injury and may be most relevant to studying the role of senescence in acute, regenerative responses to injury (Le Clef et al. 2016). Furthermore, it should be kept in mind that most rodent experimental models of renal disease are performed in relatively young animals, potentially affecting their relevance to the aging kidney. As for understanding the role of cellular senescence in progression from acute to chronic kidney injury, and in CKD itself. The chronic 

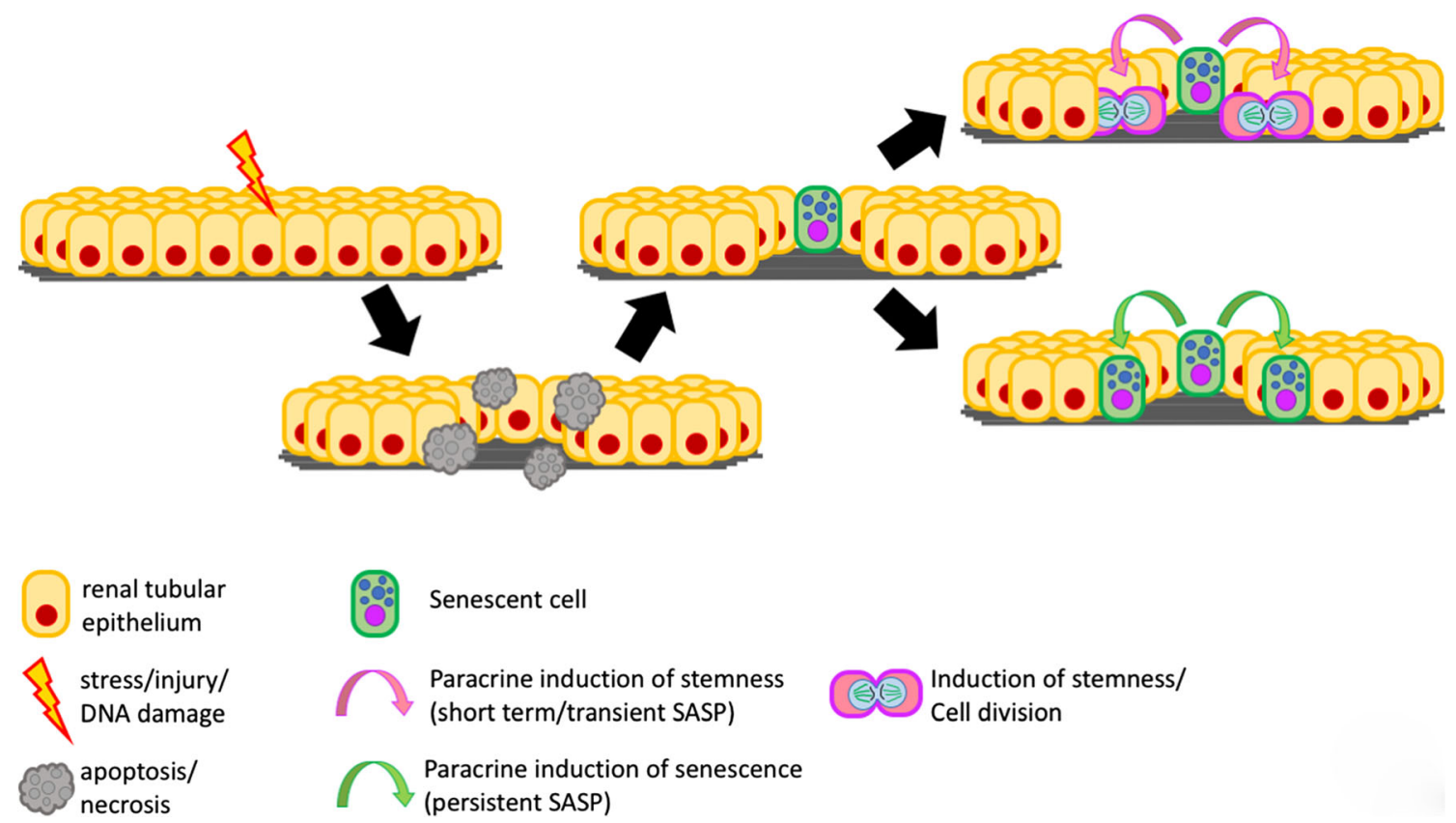

Fig. 3 Paracrine effects of senescent cells in early and late phases of tissue injury

IRI and multiple hit models with their cumulative, diverse stresses, and also the observations on senescent cell depletion during normal and accelerated aging will be most relevant (Bonventre 2014a; Le Clef et al. 2016; Sturmlechner et al. 2017).

\section{Pharmaceutical senotherapies}

Clearance of senescent cells through transgenic depletion has revealed promising beneficial effects on kidney homeostasis during aging and upon damage. For translational purposes, development of non-transgenic intervention is now of major interest and treatment with several different compounds targeting a variety of senescence-associated pathways are under study. These so-called senotherapies can be broadly divided according to three different approaches (Childs et al. 2015):

\section{Prevention of senescence}

The first approach is to prevent senescence by limiting triggers inducing senescence through lifestyle and anti-aging drugs (e.g. caloric restriction, antioxidant agents, etc.), and by inhibiting pro-inflammatory pathways. The role of cellular senescence in the renal effects of successful lifestyle interventions linked with extended (healthy) lifespan, such as a healthy diet, exercise and avoidance of smoking, is not clear. However, such a role would be compatible with the known efficacy of caloric restriction in rats, where it extended healthy lifespan and also reduced oxidative DNA damage, pro- inflammatory factors, senescence and fibrosis in the kidney (Heydari et al. 2007; Ning et al. 2013; Xu et al. 2015). The life extending effect of caloric restriction in rodents is mediated through the MAPK and mTOR growth promoting pathways, which are linked to the SASP (Inoki et al. 2012). Antioxidants might be beneficial by reducing ROS-mediated DNA damage and thereby preventing DDR-induced senescence (Holmström and Finkel 2014). Mitochondria-targeted therapy with SS-31 (also known as Elamipretide) is thought to stabilize cardiolipin on the inner mitochondrial membrane, thereby limiting mitochondrial dysfunction (Kloner et al. 2015). Administration of this peptide reduces senescence of renal parietal epithelial cells (PECs) in aged mice, accompanied by attenuated glomerulosclerosis in treated mice compared to controls (Sweetwyne et al. 2017). The authors link these results to the detrimental effect of mitochondrial dysfunction, indicated by the observations that PECs of treated mice display reduced mitochondrial damage (also observed in podocytes), reduced upregulation of the ROS-generating enzyme Nox4, and reduced senescence compared to controls. Moreover, 8 weeks of treatment with Elamipretide results in increased PEC density and attenuated PEC activation, but also led to reduced podocyte injury, and increased glomerular endothelial capillary integrity. Metformin also reduces the production of ROS (Algire et al. 2012).

\section{Elimination of senescent cells}

The second approach is to aim at the removal of senescent cells. So called 'senolytics' interfere with anti-apoptotic and 
pro-survival signaling, thereby eliminating senescent cells (Zhu et al. 2015). Senescent cells have much in common with cancer cells, including similarities in metabolic activity, the DDR and activation of pro-survival pathways or inhibition of pro-apoptotic pathways (Ghosal and Chen 2013; Dörr et al. 2013). Therefore, similar strategies used for mediating apoptosis in cancer cells, are explored for removal of senescent cells. In other words, antitumor drugs are investigated for their potential as senolytic agents. ABT-263 (also known as navitoclax) is one of the most widely studied senolytic agents. It is regarded as a pan-BCL inhibitor, as it is known to cause apoptosis in various cell types by inhibiting the anti-apoptotic BCL family members, including BCL-2, BCL-XL and BCLW (Chang et al. 2016; Yosef et al. 2016). However, navitoclax has not yet been tested for its impact on viability, phenotype, and function of kidney cells in vitro or in vivo. Other agents studied for targeting senescent cells (although also not in the kidney) include the cancer drugs quercetin and dasatinib (Zhu et al. 2015). These anti-tumor agents are known for inhibiting a broad spectrum of protein kinases and tyrosine kinases(O'Hare et al. 2005; Russo et al. 2012). In vitro, quercetin and dasatinib reduce expression of the anti-apoptotic regulator PAI-2 and induce apoptosis in senescent primary human pre-adipocytes and HUVECs, respectively (Zhu et al. 2015). In vivo, combined administration of quercetin and dasatinib leads to reduced markers of senescence (SA- $\beta$-Gal and p16) in fat and liver tissue from old mice, and to functional improvement. However, the effect of these drugs has been reported to be non-specific as it remains unclear in how far they are due to senescent cell depletion, or secondary to intervention in a multitude of unrelated pathways (Chang et al. 2016). More recently, the selective BCL-XL inhibitors A1331852 and A1155463, were identified as potential senolytics, inducing senescence-specific apoptosis in human umbilical vein endothelial cells (HUVECs) and human lung fibroblast (IMR90) (Zhu et al. 2017). As selective BCL-XL inhibitors, they may have less hematological toxicity than navitoclax.

Elimination of senescent cells may also be induced by Fisetin, a naturally occurring flavone that causes senescencespecific apoptosis in HUVECs, and by the natural product piperlongumine which caused apoptosis of senescent human WI-38 fibroblasts, no matter whether senescence was induced by either ionizing radiation, or replicative exhaustion, or ectopic expression of the Ras oncogene (Zhu et al. 2016; Wang et al. 2016). The precise mechanism of action by which fisetin and piperlongumine induce apoptosis in senescent cells still remains unclear.

Another possible target for interfering in the apoptotic balance is CCN2 which is part of the SASP. In human mesangial cells, CCN2 stabilizes the anti-apoptotic protein Bcl-2, by activation of MAPK phosphatase-1 (MKP-1), resulting in reduced apoptosis and cell survival (Wahab et al. 2007). In addition, CCN2 plays a key role in the pathogenesis of kidney disease and can activate profibrotic pathways. Theoretically, targeting senescence-induced CCN2 might thus have beneficial effects at multiple levels, including triggering apoptosis of senescent cells. Indeed, genetic silencing of MKP-1 using siRNA or antisense oligonucleotides was able to induce cell apoptosis in mesangial cells treated with CCN2 (Wahab et al. 2007). However, direct evidence for CCN2-induced upregulation of anti-apoptotic proteins in the context of senescence is lacking. Additionally, the tumor suppressor p53, a known target for cancer treatment, can also be targeted for halting senescence. The FOXO4-D-Retro-Inverso(DRI) peptide (also known as Proxofim) selectively induces targeted apoptosis of senescent cells (TASC) by competing with normal antiapoptotic FOXO4-p53 binding (Baar et al. 2017). Similar to trans-genetic elimination of senescent cells discussed above, administration of FOXO4DRI cell-penetrating peptide reduced tubular senescent cell numbers, preserving and even restoring renal function in both rapidly aging trichothiodystrophy (TTD) mice and naturally aging wild type mice. As discussed above, these promising data should be seen in the context that several possible adverse effects of eliminating senescent cells have been pointed out, including impaired cutaneous wound healing and increased fibrosis upon liver damage, underscoring the critical positive contribution of naturally occurring cellular senescence to (acute) regenerative processes (Krizhanovsky et al. 2008; Demaria et al. 2014). Another, maybe largely theoretical, consideration might be that application of senolytics in advanced disease states with high numbers of accumulated senescent cells, might lead to a cell lysis syndrome due to sudden elimination of massive numbers of senescent cells. In most known conditions, however, this seems unlikely as senescent cells only seem to make up for a small percentage of total cells.

\section{Modulation of the SASP}

SASP modulating drugs target pro-inflammatory signaling pathways such as NF-KB, JNK or p38 MAPK. SP600125 is an inhibitor of c-Jun N-terminal kinase (JNK), a member of the growth promoting pathway MAPK playing an essential role in inflammatory responses, including the SASP (Bennett et al. 2001). In the kidney, G2-arrested PTCs activate JNK-signaling, thereby upregulating profibrotic cytokines like CCN2 and TGF- $\beta$ As discussed above (Yang et al. 2010), IRI after treatment with a SP600125 (a pan-JNK inhibitor) leads to lower numbers of senescent cells in G2-phase and reduces fibrosis (Yang et al. 2010). The pro-inflammatory pathways of the SASP can also be targeted by the mTOR inhibitor rapamycin or the AMPK activator metformin, leading to prevention of senescence (Iglesias-Bartolome et al. 2012; Noren Hooten et al. 2016). Although SASP modulation 
is expected to limit detrimental paracrine effects of prolonged presence of senescent cells, SASP modulation could also lead to harmful side-effects. First, SASP factors are not senescence-specific but are upregulated in a broad spectrum of different pathways, and intervention could thus interfere with vital processes. Secondly, SASP modulation could impede immune surveillance, and hamper elimination of senescent cells.

\section{Stimulating senescence}

Strikingly, certain triggers inducing senescence ultimately limit rather than stimulate fibrosis in various organs and conditions. For instance, the matricellular protein CCN1 (also known as CYR61) induces senescence of fibroblasts in cutaneous wound healing and of liver myofibroblasts in hepatic injury, and its expression is linked to reduced fibrosis (Jun and Lau 2010; Kim et al. 2013). Therefore, CCN1-induced senescence might be used as therapy to limit fibrosis. Although its role in the kidney remains unclear, $\mathrm{CCN} 1$ expression is also elevated in several senescence-associated human pathologies beyond the liver, including atherosclerosis, which suggests a possible role in age-related diseases (Littlewood and Bennett 2007). On the other hand, the expression of CCN2, another, closely related, member of the $\mathrm{CCN}$ protein family, is associated with fibrosis of different organs, including the liver (Krizhanovsky et al. 2008). This indicates that the dual role of senescence on fibrosis is dependent on varying triggers.

\section{Targeting strategies}

Currently available senolytic drugs have several limitations, the major challenge being to target the right cells at the right time. The clinical applicability of systemically administered senolytic drugs is impeded by dose limiting side-effects on other organs. For instance, navitoclax caused dosedependent thrombocytopenia, due to inhibition of BCL-X in platelets resulting in platelet apoptosis (Mason et al. 2007; Zhang et al. 2007; Wilson et al. 2010). Theoretically, such limitations of senolytic drugs may be overcome by targeted delivery to specific organs and cell types or by specific targeting of senescent cells.

Targeted accumulation of senolytic agents in the kidney might be achieved using nanomedicines (i.e. nanoparticulate carriers) like conjugates and liposomes. Delivery of therapeutic of such functionalized compounds should enable high enough drug concentrations where needed, while sharply limiting systemic drug exposure and thereby side effects. The delivery of an effective senolytic drug dose inside targeted cells would be accomplished by internalization of the functionalized compound triggered by binding to the cell surface receptors specifically expressed by certain cell types in the kidney (Falke et al. 2015). There is a variety of compounds that can carry therapeutic agents, including glucosamine conjugates, poly vinylpyrrolidone (PVP)-derivatives, lysozyme conjugates and other low molecular weight protein (LMWP)carriers, and also the targeting peptide (KKEEE) $3 \mathrm{~K}$ (Franssen et al. 1993; Kamada et al. 2003; Lin et al. 2013; Falke et al. 2015; Wischnjow et al. 2016). The kidney is eminently qualified for such targeting strategies, as kidney cells possess several relatively specific cell surface receptors, including LDL receptor-related protein 2 (commonly known as megalin/ cubulin), integrin $\alpha 8$, E-selectin, podocyte-specific antigen and folate receptor $1 \alpha$ (Falke et al. 2015).

Targeting of PTCs, which display features of senescence with aging and pathology, may be the most promising approach, as these cells are highly active in accumulating compounds from the filtered urine via their receptors in the luminal brush-border (Christensen et al. 2012). Among these, megalin and folate receptor $1 \alpha$ have been successfully employed for targeting the proximal tubular epithelium (Prakash et al. 2008; Shillingford et al. 2012). Another promising approach to target PTCs is the therapeutic use of small interfering RNA (siRNA). In mouse models of ischemic and cisplatininduced acute kidney injury, intravenous administration of siRNA against p53 reduces cellular p53 and attenuates p53mediated apoptosis (Molitoris et al. 2009). The validity of this approach is currently being addressed in a phase 3 clinical trial testing p53 siRNA for preservation of kidney function after major cardiothoracic surgery.

Targeting other renal cell types (i.e. mesangial cells, endothelial cells and podocytes) is theoretically possible through targeting of different surface receptors, using nanoparticles, or with liposomes(Tuffin et al. 2005; Choi et al. 2011; Kamaly et al. 2016). For instance, mesangial cells, that predominantly become senescent as a consequence of hypertension and diabetic nephropathy, have been targeted through integrin $\alpha 8$ and Thy 1.1 using liposomes in rodents(Scindia et al. 2008; Suana et al. 2011).

\section{Summary and future}

In the kidney, both G1- and G2-arrested senescent cells accumulate with advancing age and renal disease in various areas, particularly in cortical proximal tubular cells. In aging mice, genetic clearance of senescent cells leads to better preservation of kidney function and morphology. In diseased kidneys, there is a time-dependent effect of senescence on the development of fibrosis, with early beneficial effects and detrimental long-term consequences. Studies examining therapeutic options for depletion of senescent cells in humans are complicated because of dose limiting side effects on other organs. 
Therefore, specific targeting of senescent cells in the kidney might be essential.

Further research is also needed to understand in how far accumulation of renal senescent cells in renal aging and disease (i) is due to increased production or reduced clearance via immune surveillance, (ii) is a direct cause or a consequence of progressive organ injury and organismal aging and (iii) if elimination of these cells (at the right time) improves kidney function and histopathological changes. Novel therapeutic approaches for elimination of senescent cells in vivo, including targeting strategies to overcome dose limiting side effects on other organs, will be important to find answers to these questions.

Open Access This article is distributed under the terms of the Creative Commons Attribution 4.0 International License (http:// creativecommons.org/licenses/by/4.0/), which permits unrestricted use, distribution, and reproduction in any medium, provided you give appropriate credit to the original author(s) and the source, provide a link to the Creative Commons license, and indicate if changes were made.

\section{References}

Aan GJ, Hairi HA, Makpol S et al (2013) Differences in protein changes between stress-induced premature senescence and replicative senescence states. Electrophoresis 34:2209-2217. https://doi.org/10. 1002/elps.201300086

d'Adda di Fagagna F (2008) Living on a break: cellular senescence as a DNA-damage response. Nat Rev Cancer 8:512-522. https://doi.org/ $10.1038 / \mathrm{nrc} 2440$

Algire C, Moiseeva O, Deschênes-Simard X et al (2012) Metformin reduces endogenous reactive oxygen species and associated DNA damage. Cancer Prev Res (Phila) 5:536-543. https://doi.org/10. 1158/1940-6207.CAPR-11-0536

Baar MP, Brandt RMC, Putavet DA et al (2017) Targeted apoptosis of senescent cells restores tissue homeostasis in response to Chemotoxicity and aging. Cell 169:132-147.e16. https://doi.org/ 10.1016/j.cell.2017.02.031

Baisantry A, Bhayana S, Rong S et al (2016) Autophagy induces Prosenescent changes in proximal tubular S3 segments. J Am Soc Nephrol 27:1609-1616. https://doi.org/10.1681/ASN.2014111059

Baker DJ, Childs BG, Durik M et al (2016) Naturally occurring p16(Ink4a)-positive cells shorten healthy lifespan. Nature 530: 184-189. https://doi.org/10.1038/nature16932

Bennett BL, Sasaki DT, Murray BW et al (2001) SP600125, an anthrapyrazolone inhibitor of Jun N-terminal kinase. Proc Natl Acad Sci U S A 98:13681-13686. https://doi.org/10.1073/pnas. 251194298

Blagosklonny MV (2011) Cell cycle arrest is not senescence. Aging (Albany NY) 3:94-101. 10.18632/aging.100281

Bonventre JV (2014a) Maladaptive proximal tubule repair: cell cycle arrest. Nephron Clin Pract 127:61-64. https://doi.org/10.1159/ 000363673

Bonventre JV (2014b) Primary proximal tubule injury leads to epithelial cell cycle arrest, fibrosis, vascular rarefaction, and glomerulosclerosis. Kidney Int Suppl 4(2011):39-44. https://doi. org/10.1038/kisup.2014.8
Braun H, Schmidt BMW, Raiss M et al (2012) Cellular senescence limits regenerative capacity and allograft survival. J Am Soc Nephrol 23: 1467-1473. https://doi.org/10.1681/ASN.2011100967

Burd CE, Sorrentino JA, Clark KS et al (2013) Monitoring tumorigenesis and senescence in vivo with a p16(INK4a)-luciferase model. Cell 152:340-351. https://doi.org/10.1016/j.cell.2012.12.010

Campisi J (1997) The biology of rep licative senescence. Eur J Cancer 33: 703-709. https://doi.org/10.1016/S0959-8049(96)00058-5

Campisi J, d'Adda di Fagagna F (2007) Cellular senescence: when bad things happen to good cells. Nat Rev Mol Cell Biol 8:729-740. https://doi.org/10.1038/nrm2233

Cesare AJ, Hayashi MT, Crabbe L, Karlseder J (2013) The telomere deprotection response is functionally distinct from the genomic DNA damage response. Mol Cell 51:141-155. https://doi.org/10. 1016/j.molcel.2013.06.006

Chang J, Wang Y, Shao L et al (2016) Clearance of senescent cells by ABT263 rejuvenates aged hematopoietic stem cells in mice. Nat Med 22:78-83. https://doi.org/10.1038/nm.4010

Chen X, Ko LJ, Jayaraman L, Prives C (1996) p53 levels, functional domains, and DNA damage determine the extent of the apoptotic response of tumor cells. Genes Dev 10:2438-2451

Chen L, Willis SN, Wei A et al (2005) Differential targeting of prosurvival $\mathrm{Bcl}-2$ proteins by their $\mathrm{BH} 3$-only ligands allows complementary apoptotic function. Mol Cell 17:393-403. https://doi. org/10.1016/j.molcel.2004.12.030

Childs BG, Durik M, Baker DJ, van Deursen JM (2015) Cellular senescence in aging and age-related disease: from mechanisms to therapy. Nat Med 21:1424-1435. https://doi.org/10.1038/nm.4000

Chkhotua AB, Gabusi E, Altimari A et al (2003) Increased expression of p16(INK4a) and p27(Kip1) cyclin-dependent kinase inhibitor genes in aging human kidney and chronic allograft nephropathy. Am J Kidney Dis 41:1303-1313

Choi CHJ, Zuckerman JE, Webster P, Davis ME (2011) Targeting kidney mesangium by nanoparticles of defined size. Proc Natl Acad Sci U S A 108:6656-6661. https://doi.org/10.1073/pnas.1103573108

Christensen EI, Birn H, Storm T et al (2012) Endocytic receptors in the renal proximal tubule. Physiology (Bethesda) 27:223-236. https:// doi.org/10.1152/physiol.00022.2012

Clements ME, Chaber CJ, Ledbetter SR, Zuk A (2013) Increased cellular senescence and vascular rarefaction exacerbate the progression of kidney fibrosis in aged mice following transient ischemic injury. PLoS One 8:e70464. https://doi.org/10.1371/journal.pone.0070464

Coppé J-P, Patil CK, Rodier F et al (2008) Senescence-associated secretory phenotypes reveal cell-nonautonomous functions of oncogenic RAS and the p53 tumor suppressor. PLoS Biol 6:2853-2868. https://doi.org/10.1371/journal.pbio.0060301

Coresh J, Selvin E, Stevens LA et al (2007) Prevalence of chronic kidney disease in the United States. JAMA 298:2038-2047. https://doi.org/ 10.1001/jama.298.17.2038

Crosio C, Fimia GM, Loury R et al (2002) Mitotic phosphorylation of histone H3: spatio-temporal regulation by mammalian aurora kinases. Mol Cell Biol 22:874-885. https://doi.org/10.1128/MCB. 22.3.874-885.2002

Datto MB, Li Y, Panus JF et al (1995) Transforming growth factor beta induces the cyclin-dependent kinase inhibitor p21 through a p53-independent mechanism. Proc Natl Acad Sci U S A 92: $5545-5549$

el-Deiry WS, Tokino T, Velculescu VE et al (1993) WAF1, a potential mediator of $\mathrm{p} 53$ tumor suppression. Cell 75:817-825

Demaria M, Ohtani N, Youssef SA et al (2014) An essential role for senescent cells in optimal wound healing through secretion of PDGF-AA. Dev Cell 31:722-733. https://doi.org/10.1016/j.devcel. 2014.11.012

Dimri GP, Lee X, Basile G et al (1995) A biomarker that identifies senescent human cells in culture and in aging skin in vivo. Proc Natl Acad Sci U S A 92:9363-9367 
Ding G, Franki N, Kapasi AA et al (2001) Tubular cell senescence and expression of TGF-beta1 and p21(WAF1/CIP1) in tubulointerstitial fibrosis of aging rats. Exp Mol Pathol 70:43-53. https://doi.org/10. 1006/exmp.2000.2346

Dörr JR, Yu Y, Milanovic M et al (2013) Synthetic lethal metabolic targeting of cellular senescence in cancer therapy. Nature 501:421425. https://doi.org/10.1038/nature12437

Falke LL, Gholizadeh S, Goldschmeding R et al (2015) Diverse origins of the myofibroblast-implications for kidney fibrosis. Nat Rev Nephrol 11:233-244. https://doi.org/10.1038/nrneph.2014.246

Franssen EJ, Moolenaar F, de Zeeuw D, Meijer DK (1993) Lowmolecular-weight proteins as carriers for renal drug targeting. Contrib Nephrol 101:99-103

Ghosal G, Chen J (2013) DNA damage tolerance: a double-edged sword guarding the genome. Transl Cancer Res 2:107-129. https://doi.org/ 10.3978/j.issn.2218-676X.2013.04.01

Gil J, Peters G (2006) Regulation of the INK4b-ARF-INK4a tumour suppressor locus: all for one or one for all. Nat Rev Mol Cell Biol 7:667-677. https://doi.org/10.1038/nrm1987

Gire V, Dulic V (2015) Senescence from G2 arrest, revisited. Cell Cycle 14:297-304. https://doi.org/10.1080/15384101.2014.1000134

Harper JW, Adami GR, Wei N et al (1993) The p21 Cdk-interacting protein Cip1 is a potent inhibitor of G1 cyclin-dependent kinases. Cell 75:805-816

Heydari AR, Unnikrishnan A, Lucente LV, Richardson A (2007) Caloric restriction and genomic stability. Nucleic Acids Res 35:7485-7496. https://doi.org/10.1093/nar/gkm860

Hill NR, Fatoba ST, Oke JL et al (2016) Global prevalence of chronic kidney disease - a systematic review and meta-analysis. PLoS One 11:e0158765. https://doi.org/10.1371/journal.pone.0158765

Hochegger K, Koppelstaetter C, Tagwerker A et al (2007) p21 and mTERT are novel markers for determining different ischemic time periods in renal ischemia-reperfusion injury. Am J Physiol Renal Physiol 292:F762-F768. https://doi.org/10.1152/ajprenal.00084. 2006

Holmström KM, Finkel T (2014) Cellular mechanisms and physiological consequences of redox-dependent signalling. Nat Rev Mol Cell Biol 15:411-421. https://doi.org/10.1038/nrm3801

Iglesias-Bartolome R, Patel V, Cotrim A et al (2012) mTOR inhibition prevents epithelial stem cell senescence and protects from radiationinduced mucositis. Cell Stem Cell 11:401-414. https://doi.org/10. 1016/j.stem.2012.06.007

Inoki K, Kim J, Guan K-L (2012) AMPK and mTOR in cellular energy homeostasis and drug targets. Annu Rev Pharmacol Toxicol 52: 381-400. https://doi.org/10.1146/annurev-pharmtox-010611134537

Jackson SP, Bartek J (2009) The DNA-damage response in human biology and disease. Nature 461:1071-1078. https://doi.org/10.1038/ nature 08467

Johmura Y, Shimada M, Misaki T et al (2014) Necessary and sufficient role for a mitosis skip in senescence induction. Mol Cell 55:73-84. https://doi.org/10.1016/j.molcel.2014.05.003

Jullien L, Mestre M, Roux P, Gire V (2013) Eroded human telomeres are more prone to remain uncapped and to trigger a G2 checkpoint response. Nucleic Acids Res 41:900-911. https://doi.org/10.1093/ nar/gks1121

Jun J-I, Lau LF (2010) The matricellular protein CCN1 induces fibroblast senescence and restricts fibrosis in cutaneous wound healing. Nat Cell Biol 12:676-685. https://doi.org/10.1038/ncb2070

Kamada H, Tsutsumi Y, Sato-Kamada K et al (2003) Synthesis of a poly(vinylpyrrolidone-co-dimethyl maleic anhydride) co-polymer and its application for renal drug targeting. Nat Biotechnol 21: 399-404. https://doi.org/10.1038/nbt798

Kamaly N, He JC, Ausiello DA, Farokhzad OC (2016) Nanomedicines for renal disease: current status and future applications. Nat Rev Nephrol 12:738-753. https://doi.org/10.1038/nrneph.2016.156
Kang T-W, Yevsa T, Woller N et al (2011) Senescence surveillance of premalignant hepatocytes limits liver cancer development. Nature 479: 547-551. https://doi.org/10.1038/nature10599

Khanna AK, Pieper GM (2007) NADPH oxidase subunits (NOX-1, p22phox, Rac-1) and tacrolimus-induced nephrotoxicity in a rat renal transplant model. Nephrol Dial Transplant 22:376-385. https:/ doi.org/10.1093/ndt/gfl608

Khoo KH, Hoe KK, Verma CS, Lane DP (2014) Drugging the p53 pathway: understanding the route to clinical efficacy. Nat Rev Drug Discov 13:217-236. https://doi.org/10.1038/nrd4236

Kim K-H, Chen C-C, Monzon RI, Lau LF (2013) Matricellular protein $\mathrm{CCN} 1$ promotes regression of liver fibrosis through induction of cellular senescence in hepatic myofibroblasts. Mol Cell Biol 33: 2078-2090. https://doi.org/10.1128/MCB.00049-13

Kitada K, Nakano D, Ohsaki H et al (2014) Hyperglycemia causes cellular senescence via a SGLT2- and p21-dependent pathway in proximal tubules in the early stage of diabetic nephropathy. $\mathrm{J}$ Diabetes Complicat 28:604-611. https://doi.org/10.1016/j. jdiacomp.2014.05.010

Kloner RA, Shi J, Dai W (2015) New therapies for reducing postmyocardial left ventricular remodeling. Ann Transl Med 3:20. https://doi.org/10.3978/j.issn.2305-5839.2015.01.13

Kracikova M, Akiri G, George A et al (2013) A threshold mechanism mediates p53 cell fate decision between growth arrest and apoptosis. Cell Death Differ 20:576-588. https://doi.org/10. 1038/cdd.2012.155

Krishnamurthy J, Torrice C, Ramsey MR et al (2004) Ink4a/Arf expression is a biomarker of aging. J Clin Invest 114:1299-1307. https:// doi.org/10.1172/JCI22475

Krizhanovsky V, Yon M, Dickins RA et al (2008) Senescence of activated stellate cells limits liver fibrosis. Cell 134:657-667. https://doi.org/ 10.1016/j.cell.2008.06.049

Krtolica A, Parrinello S, Lockett S et al (2001) Senescent fibroblasts promote epithelial cell growth and tumorigenesis: a link between cancer and aging. Proc Natl Acad Sci U S A 98:12072-12077. https://doi.org/10.1073/pnas.211053698

Le Clef N, Verhulst A, D'Haese PC, Vervaet BA (2016) Unilateral renal ischemia-reperfusion as a robust model for acute to chronic kidney injury in mice. PLoS One 11:e0152153. https://doi.org/10.1371/ journal.pone. 0152153

Lee DH, Wolstein JM, Pudasaini B, Plotkin M (2012) INK4a deletion results in improved kidney regeneration and decreased capillary rarefaction after ischemia-reperfusion injury. Am J Physiol Renal Physiol 302:F183-F191. https://doi.org/10. 1152/ajprenal.00407.2011

Lin Y, Li Y, Wang X et al (2013) Targeted drug delivery to renal proximal tubule epithelial cells mediated by 2 -glucosamine. J Control Release 167:148-156. https://doi.org/10.1016/j.jconrel.2013.02.001

Littlewood TD, Bennett MR (2007) Foxing smooth muscle cells: FOXO3a-CYR61 connection. Circ Res 100:302-304. https://doi. org/10.1161/01.RES.0000259101.39931.d3

Liu J, Yang J-R, He Y-N et al (2012a) Accelerated senescence of renal tubular epithelial cells is associated with disease progression of patients with immunoglobulin a (IgA) nephropathy. Transl Res 159: 454-463. https://doi.org/10.1016/j.trs1.2011.11.008

Liu J, Yang J-R, He Y-N et al (2012b) Accelerated senescence of renal tubular epithelial cells is associated with disease progression of patients with immunoglobulin a (IgA) nephropathy. Transl Res 159: 454-463. https://doi.org/10.1016/j.trsl.2011.11.008

Löbrich M, Jeggo PA (2007) The impact of a negligent G2/M checkpoint on genomic instability and cancer induction. Nat Rev Cancer 7:861869. https://doi.org/10.1038/nrc2248

Lu D, Rauhauser A, Li B et al (2016) Loss of Glis2/NPHP7 causes kidney epithelial cell senescence and suppresses cyst growth in the Kif3a mouse model of cystic kidney disease. Kidney Int 89:1307-1323. https://doi.org/10.1016/j.kint.2016.03.006 
Malaquin N, Carrier-Leclerc A, Dessureault M, Rodier F (2015) DDRmediated crosstalk between DNA-damaged cells and their microenvironment. Front Genet 6:94. https://doi.org/10.3389/fgene.2015. 00094

Mao S, Xu H, Zou L et al (2014) Estrogen preserves split renal function in a chronic complete unilateral ureteral obstruction animal model. Exp Ther Med 7:1555-1562. https://doi.org/10.3892/etm.2014.1663

Mason KD, Carpinelli MR, Fletcher JI et al (2007) Programmed anuclear cell death delimits platelet life span. Cell 128:1173-1186. https:// doi.org/10.1016/j.cell.2007.01.037

Matjusaitis M, Chin G, Sarnoski EA, Stolzing A (2016a) Biomarkers to identify and isolate senescent cells. Ageing Res Rev 29:1-12. https://doi.org/10.1016/j.arr.2016.05.003

Matjusaitis M, Chin G, Sarnoski EA, Stolzing A (2016b) Biomarkers to identify and isolate senescent cells. Ageing Res Rev 29:1-12. https://doi.org/10.1016/j.arr.2016.05.003

Megyesi J, Andrade L, Vieira JM et al (2001) Positive effect of the induction of $\mathrm{p} 21 \mathrm{WAF} 1 / \mathrm{CIP} 1$ on the course of ischemic acute renal failure. Kidney Int 60:2164-2172. https://doi.org/10.1046/j.15231755.2001.00044.x

Melk A, Kittikowit W, Sandhu I et al (2003) Cell senescence in rat kidneys in vivo increases with growth and age despite lack of telomere shortening. Kidney Int 63:2134-2143. https://doi.org/10.1046/ j.1523-1755.2003.00032.x

Melk A, Schmidt BMW, Takeuchi O et al (2004) Expression of p16INK4a and other cell cycle regulator and senescence associated genes in aging human kidney. Kidney Int 65:510-520. https://doi. org/10.1111/j.1523-1755.2004.00438.x

Melk A, Schmidt BMW, Vongwiwatana A et al (2005) Increased expression of senescence-associated cell cycle inhibitor p16INK4a in deteriorating renal transplants and diseased native kidney. Am J Transplant 5:1375-1382. https://doi.org/10.1111/j.1600-6143. 2005.00846.x

Melk A, Schmidt BMW, Braun H et al (2009) Effects of donor age and cell senescence on kidney allograft survival. Am J Transplant 9: 114-123. https://doi.org/10.1111/j.1600-6143.2008.02500.x

Molitoris BA, Dagher PC, Sandoval RM et al (2009) siRNA targeted to p53 attenuates ischemic and cisplatin-induced acute kidney injury. $\mathrm{J}$ Am Soc Nephrol 20:1754-1764. https://doi.org/10.1681/ASN. 2008111204

Ning Y-C, Cai G-Y, Zhuo L et al (2013) Short-term calorie restriction protects against renal senescence of aged rats by increasing autophagic activity and reducing oxidative damage. Mech Ageing Dev 134:570-579. https://doi.org/10.1016/j.mad.2013.11.006

Noren Hooten N, Martin-Montalvo A, Dluzen DF et al (2016) Metformin-mediated increase in DICER1 regulates microRNA expression and cellular senescence. Aging Cell 15:572-581. https:// doi.org/10.1111/acel.12469

O'Hare T, Walters DK, Stoffregen EP et al (2005) In vitro activity of BcrAbl inhibitors AMN107 and BMS-354825 against clinically relevant imatinib-resistant $\mathrm{Abl}$ kinase domain mutants. Cancer Res 65: 4500-4505. https://doi.org/10.1158/0008-5472.CAN-05-0259

O'Sullivan ED, Hughes J, Ferenbach DA (2017) Renal aging: causes and consequences. J Am Soc Nephrol 28:407-420. https://doi.org/10. 1681/ASN.2015121308

Park J-Y, Schutzer WE, Lindsley JN et al (2007) p21 is decreased in polycystic kidney disease and leads to increased epithelial cell cycle progression: roscovitine augments p21 levels. BMC Nephrol 8:12. https://doi.org/10.1186/1471-2369-8-12

Prakash J, de Borst MH, Lacombe M et al (2008) Inhibition of renal rho kinase attenuates ischemia/reperfusion-induced injury. J Am Soc Nephrol 19:2086-2097. https://doi.org/10.1681/ASN.2007070794

Quimby JM, Maranon DG, Battaglia CLR et al (2013) Feline chronic kidney disease is associated with shortened telomeres and increased cellular senescence. Am J Physiol Renal Physiol 305:F295-F303. https://doi.org/10.1152/ajprenal.00527.2012
Ritschka B, Storer M, Mas A et al (2017) The senescenceassociated secretory phenotype induces cellular plasticity and tissue regeneration. Genes Dev 31:172-183. https://doi. org/10.1101/gad.290635.116

Rodier F, Muñoz DP, Teachenor R et al (2011) DNA-SCARS: distinct nuclear structures that sustain damage-induced senescence growth arrest and inflammatory cytokine secretion. J Cell Sci 124:68-81. https://doi.org/10.1242/jcs.071340

Russo M, Spagnuolo C, Tedesco I et al (2012) The flavonoid quercetin in disease prevention and therapy: facts and fancies. Biochem Pharmacol 83:6-15. https://doi.org/10.1016/j.bcp.2011.08.010

Samuels-Lev Y, O'Connor DJ, Bergamaschi D et al (2001) ASPP proteins specifically stimulate the apoptotic function of p53. Mol Cell 8:781794. https://doi.org/10.1038/35101044

Scindia Y, Deshmukh U, Thimmalapura P-R, Bagavant H (2008) Antialpha8 integrin immunoliposomes in glomeruli of lupus-susceptible mice: a novel system for delivery of therapeutic agents to the renal glomerulus in systemic lupus erythematosus. Arthritis Rheum 58: 3884-3891. https://doi.org/10.1002/art.24026

Serrano M, Hannon GJ, Beach D (1993) A new regulatory motif in cellcycle control causing specific inhibition of cyclin D/CDK4. Nature 366:704-707. https://doi.org/10.1038/366704a0

Sharpless NE, Sherr CJ (2015) Forging a signature of in vivo senescence. Nat Rev Cancer 15:397-408. https://doi.org/10.1038/nrc3960

Shillingford JM, Leamon CP, Vlahov IR, Weimbs T (2012) Folateconjugated rapamycin slows progression of polycystic kidney disease. J Am Soc Nephrol 23:1674-1681. https://doi.org/10.1681/ ASN.2012040367

Sis B, Tasanarong A, Khoshjou F et al (2007) Accelerated expression of senescence associated cell cycle inhibitor p16INK4A in kidneys with glomerular disease. Kidney Int 71:218-226. https://doi.org/ 10.1038/sj.ki.5002039

Smith JR, Pereira-Smith OM (1996) Replicative senescence: implications for in vivo aging and tumor suppression. Science 273:63-67

Stein GH, Dulić V (1995) Origins of G1 arrest in senescent human fibroblasts. BioEssays 17:537-543. https://doi.org/10.1002/bies. 950170610

Sturmlechner I, Durik M, Sieben CJ et al (2017) Cellular senescence in renal ageing and disease. Nat Rev Nephrol 13:77-89. https://doi. org/10.1038/nrneph.2016.183

Suana AJ, Tuffin G, Frey BM et al (2011) Single application of low-dose mycophenolate mofetil-OX7-immunoliposomes ameliorates experimental mesangial proliferative glomerulonephritis. J Pharmacol Exp Ther 337:411-422. https://doi.org/10.1124/jpet.110.176222

Sweetwyne MT, Pippin JW, Eng DG et al (2017) The mitochondrialtargeted peptide, SS-31, improves glomerular architecture in mice of advanced age. Kidney Int 91:1126-1145. https://doi.org/10.1016/ j.kint.2016.10.036

Toussaint O, Dumont P, Dierick JF et al (2000) Stress-induced premature senescence. Essence of life, evolution, stress, and aging. Ann N Y Acad Sci 908:85-98

Tuffin G, Waelti E, Huwyler J et al (2005) Immunoliposome targeting to mesangial cells: a promising strategy for specific drug delivery to the kidney. J Am Soc Nephrol 16:3295-3305. https://doi.org/10.1681/ ASN.2005050485

Verzola D, Gandolfo MT, Gaetani G et al (2008) Accelerated senescence in the kidneys of patients with type 2 diabetic nephropathy. Am J Physiol Renal Physiol 295:F1563-F1573. https://doi.org/10.1152/ ajprenal.90302.2008

Wahab N, Cox D, Witherden A, Mason RM (2007) Connective tissue growth factor (CTGF) promotes activated mesangial cell survival via up-regulation of mitogen-activated protein kinase phosphatase1 (MKP-1). Biochem J 406:131-138. https://doi.org/10.1042/ BJ20061817 
Wang Y, Chang J, Liu X et al (2016) Discovery of piperlongumine as a potential novel lead for the development of senolytic agents. Aging (Albany NY) 8:2915-2926. 10.18632/aging.101100

Westhoff JH, Hilgers KF, Steinbach MP et al (2008) Hypertension induces somatic cellular senescence in rats and humans by induction of cell cycle inhibitor p16INK4a. Hypertension 52:123-129. https:// doi.org/10.1161/HYPERTENSIONAHA.107.099432

Wilson WH, O'Connor OA, Czuczman MS et al (2010) Navitoclax, a targeted high-affinity inhibitor of BCL-2, in lymphoid malignancies: a phase 1 dose-escalation study of safety, pharmacokinetics, pharmacodynamics, and antitumour activity. Lancet Oncol 11:11491159. https://doi.org/10.1016/S1470-2045(10)70261-8

Wischnjow A, Sarko D, Janzer M et al (2016) Renal targeting: peptidebased drug delivery to proximal tubule cells. Bioconjug Chem 27: 1050-1057. https://doi.org/10.1021/acs.bioconjchem.6b00057

Wolstein JM, Lee DH, Michaud J et al (2010) INK4a knockout mice exhibit increased fibrosis under normal conditions and in response to unilateral ureteral obstruction. Am J Physiol Renal Physiol 299:F1486-F1495. https://doi.org/10.1152/ ajprenal.00378.2010

Xu X-M, Ning Y-C, Wang W-J et al (2015) Anti-Inflamm-aging effects of long-term caloric restriction via overexpression of SIGIRR to inhibit NF-KB signaling pathway. Cell Physiol Biochem 37:1257-1270. https://doi.org/10.1159/000430248

Xue W, Zender L, Miething C et al (2007) Senescence and tumour clearance is triggered by p53 restoration in murine liver carcinomas. Nature 445:656-660. https://doi.org/10.1038/nature05529
Yang L, Besschetnova TY, Brooks CR, et al (2010) Epithelial cell cycle arrest in G2/M mediates kidney fibrosis after injury. Nat Med 16:535-43- 1p following 143. doi:https://doi.org/ $10.1038 / \mathrm{nm} .2144$

Yosef R, Pilpel N, Tokarsky-Amiel R et al (2016) Directed elimination of senescent cells by inhibition of BCL-W and BCL-XL. Nat Commun 7:11190. https://doi.org/10.1038/ncomms 11190

Zhang H, Xiong Y, Beach D (1993) Proliferating cell nuclear antigen and p21 are components of multiple cell cycle kinase complexes. Mol Biol Cell 4:897-906

Zhang H, Nimmer PM, Tahir SK et al (2007) Bcl-2 family proteins are essential for platelet survival. Cell Death Differ 14:943-951. https:// doi.org/10.1038/sj.cdd.4402081

Zhou H, Kato A, Yasuda H et al (2004) The induction of cell cycle regulatory and DNA repair proteins in cisplatin-induced acute renal failure. Toxicol Appl Pharmacol 200:111-120. https://doi.org/10. 1016/j.taap.2004.04.003

Zhu Y, Tchkonia T, Pirtskhalava T et al (2015) The Achilles' heel of senescent cells: from transcriptome to senolytic drugs. Aging Cell 14:644-658. https://doi.org/10.1111/acel.12344

Zhu Y, Tchkonia T, Fuhrmann-Stroissnigg H et al (2016) Identification of a novel senolytic agent, navitoclax, targeting the Bcl-2 family of anti-apoptotic factors. Aging Cell 15:428-435. https://doi.org/10. 1111/acel.12445

Zhu Y, Doornebal EJ, Pirtskhalava T et al (2017) New agents that target senescent cells: the flavone, fisetin, and the BCL-XL inhibitors, A1331852 and A1155463. Aging (Albany NY) 9:955-963. 10. 18632/aging.101202 